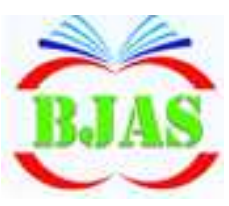

ISSN $1814-5868$
Available online at http://journal.bajas.edu.iq

College of Agriculture, University of Basrah

DOi:10.21276/basjas

Basrah J. Agric. Sci., 31(1): 78-84, 2018

\section{Basrah Journal of Agricultural Sciences}

E-ISSN: 2520-0860

\title{
Effect of Storage on the Antioxidant Activity of Yolk Lipid for Some Kinds of Eggs
}

\section{Sara H.M. Shareef* \& Aum-El Bashar H.J. Al-Moussawi}

Department of Food Sciences and Biotechnology, College of Agriculture, University of Basrah, Basrah, Iraq

*Corresponding author: e-mail: sarahashem1979@gmail.com

Received 8 March 2018; Accepted 12 October 2018; Available online 8 November 2018

\begin{abstract}
The current study included estimating the antioxidant activity of yolk lipid for the quail egg, Coturnix japonica (quail), Gallus gallus L. (hen), Anas Platyrhynchos L. (duck) and Gygnus cygnus L.(goose). The yolk and the white of those were separated from each other and the yolk lipid was separated also. The antioxidant activity, reducing power, chelating of iron ions and scavenging of hydrogen peroxide of yolk lipid for fresh egg were studied. The effect of egg storage at laboratory temperature $\left(25-30^{\circ} \mathrm{C}\right)$ and refrigerator temperature $\left(4 \pm 1^{\circ} \mathrm{C}\right)$ on antioxidant activity of egg yolk lipid was studied. The results showed that there was a significant decrease $(\mathrm{P}<0.05)$ in all the antioxidant activity tests with duration of storage compared to yolk lipid of fresh egg. The decrease was more obvious when storing the egg at lab temperature $\left(25-30^{\circ} \mathrm{C}\right)$ compared with the stored egg in refrigeration $\left(4 \pm 1^{\circ} \mathrm{C}\right)$.
\end{abstract}

Keywords: Antioxidant activity, Egg yolk lipid, Duck, Goose, Hen, Quil.

\section{Introduction}

Egg is one of the most important sources of human nutrition and most receptive, as it provides the body with the needs of the main nutrients. The edible section consists of water $(74 \%)$ and proteins $(12 \%)$ and lipids $(12 \%)$ and carbohydrates $(1 \%)$, in addition to vitamins and minerals and many antioxidants (Anton et al., 2007; Li-Chan \& Kim, 2008).

Most egg lipids are found in yolk and $65 \%$ of yolk lipids are triglycerides, in fact there are $30 \%$ phospholipids and $4 \%$ cholesterol in addition to carotenoids (Hatta et al., 2008).
Saturated fatty acids (SFA) form $30-35 \%$ of total fatty acids and $40-45 \%$ monounsaturated fatty acids (MUFA), while Polyunsaturated Fatty Acids (PUFA) are 20-25\% (Nimalaratne \& Wu, 2015; Anton et al., 2007).

Yolk is a rich source of antioxidant, it contains many compounds such as carotenoids, tochopherol, free amino acids, phosvitin and aromatic amino acids. Carotenoids are the main contributors to the presence of antioxidant properties of egg yolk, carotenoids which include leutin, 
zeaxanthin and aromatic amino acids such as tryptophan and tyrosine which have antioxidant activity. Phosvitin of egg yolk is a good source of antioxidant activity as being holder of metals such as iron. Selenium is also an important source of antioxidant activity (Nimalaratne et al., 2015).

Antioxidants have been given a wide attention to nutritionists and researchers in the medical field because of their direct effects in reducing the risk of chronic diseases such as cancer, heart disease, and aging. In addition, it also reduces the oxidation and destruction of DNA in the human body and delays the onset of oxidative rancidity which produces compounds that responsible for the unwanted flavor in them or causes changes in the color and loss in nutritional value or formation toxic compounds that will effect on the human health. So it requires an addition of antioxidants to prevent oxidation of lipids or destruction of vitamins or prevent the formation of free radicals resulting from oxidation of lipids, such as the species of active oxygen as the radical of hydroxyl and single oxygen and hydrogen peroxide. Free radicals are unstable and very effective and able to break the biological molecules which include DNA, proteins, high lipid, and carbohydrates (Surai, 2006).

\section{Materials and Methods:}

Eggs of a quail Cotturnix japonica was purchased from the animal field of the College of Agriculture, University of Basrah. The local hen egg (Iraqi origin), Gallus gallus and the local duck egg. Anas platyrhynchos L. and local goose egg Cygnus cygnus were purchased from local markets in Basrah.

The egg were washed well with water and after the drying was stored in plastic containers and stored at laboratory temperature $\left(25-30^{\circ} \mathrm{c}\right)$ and then at refrigeration $\left(4 \pm 1^{\circ} \mathrm{c}\right)$ in different storage periods (15, 30, 45 and 60-days). After that each egg was broken manually and the white was separated from the yolk, the yolk lipid was separated from the protein by solvent process and then was frozen in plastic containers during the above storage periods.
The percentage of lipid was estimated by the method of Pearson (1970) and mentioned in Al-Tai \& Al-Moussawi, (1992).

Antioxidant activity was estimated using linoleic acid according to the method of Osawa \& Namiki (1981) that mentioned in Al-Hilfi (2016).

Equation of reducing power was estimated by Oyaizu (1986) method mentioned in Chen et al. (2009).

Chelating of iron ions was measured according to the method created by Decker \& Welch (1990) mentioned in Al-Hilfi \& AlMoussawi (2011).

Scavenging of hydrogen peroxide measured by Ruch et al. (1989) method mentioned in Gulcin (2005).

The complete random design (C.R.D) was used by the ready statistical program (SPSS, 2009), these factors were tested by using the least significant difference (L.S.D) test at probability level of 0.05 .

\section{Result and Discussion}

\section{Effect of storage on the Antioxidant activity of yolk lipid}

The fig. (1) shows the effect of storage on antioxidant activity of yolk lipid for quail, hen, duck and goose egg. There were significantly different $(\mathrm{P}<0.05)$ in the antioxidant activity values of yolk lipid for the egg that stored at laboratory temperature (A) and stored at refrigeration (B), whereas the antioxidant activity of yolk lipid decreased continuously during the storage period and the reduction of activity was more in the egg that stored in the laboratory.

Fig. (1-A), the antioxidant activity of yolk lipid stored at laboratory temperature decreased from $60.04 \%, 62.18 \%, 61.66 \%$ and $65.33 \%$ of quail, hen, duck and goose eggs yolk respectively before storage to $47.36 \%$, $49.72 \%, 48.93 \%$ and $50.71 \%$ for the above four types respectively after 45-days of storage. 

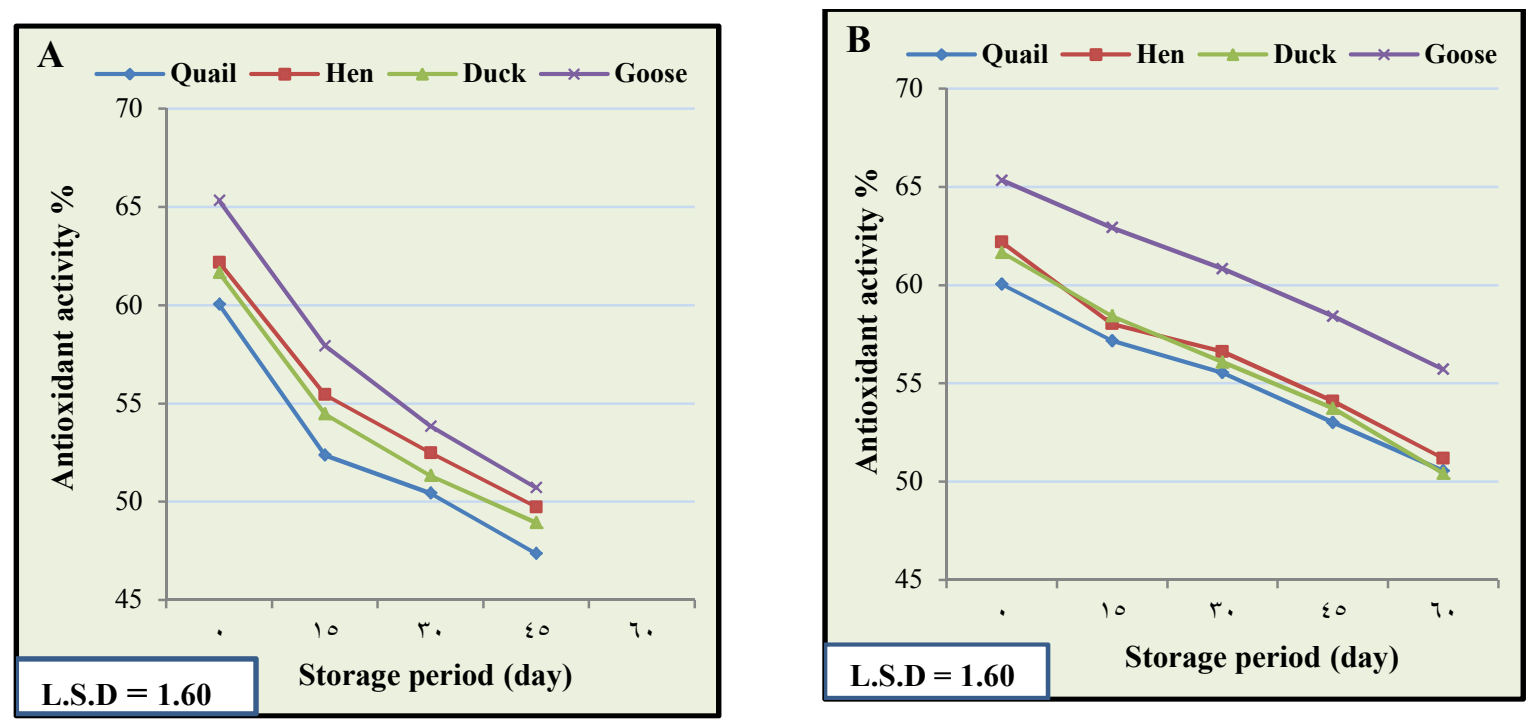

Fig. (1): Effect of storage on the antioxidant activity of yolk lipid, A: Laboratory temperature (25-30) ${ }^{\circ} \mathrm{C}$, B: Refrigerator temperature $(4 \pm 1){ }^{\circ} \mathrm{C}$.

Fig. (1-B) Also shows the antioxidant activity values of eggs yolk lipid stored in refrigeration $\left(4 \pm 1^{\circ} \mathrm{C}\right)$ for 60 -days and there was reduction less than that was stored in the laboratory. The values of activity at end of the storage period (60-days) were $50.55 \%$, $51.18 \%, 50.42 \%$ and $55.71 \%$ for egg types respectively. This was indicated by Akter et al. (2014) whereas their study was the effect of storage on the antioxidant activity of the hen egg, where they observed a significant increase in the oxidation of the yolk lipid of hen egg by increasing the storage period at a different temperatures. This agrees with Lakins et al. (2009), where they found that is egg storage for (30-90) days at $\left(4 \pm 1^{\circ} \mathrm{C}\right)$ led to increase the value of Thiobarbituric acid, while storage at room temperature increased

the value of Thiobarbituric acid and the reason for that was explained that is the reduction of vitamin $\mathrm{E}$ content in stored egg.

\section{Effect of storage on the Reducing power of yolk lipid}

The results in Fig. (2) refer to the effect of storage on the reducing power of the yolk lipid that was stored at laboratory temperature (A). The results showed there was significant differences $(\mathrm{P}<0.05)$ for the values of reducing power between the egg types studied and there was significant effect for the storage ( $\mathrm{P}<0.05)$ on the reducing power values, when observed decreasing in reducing power with continuous of storage period. The values of quail, hen, duck and goose before storage were 1.352, 1.392, 1.497 and 1.403 respectively; however, the values of those have decreased to $1.132,1.153,1.342$ and1.302 respectively after 15-days, and continued the decreasing to the end of the storage period (45-days), as it reached 0.934, $0.902,1.000$ and 1.000, respectively. -

When the egg were stored in the refrigerator $\left(4 \pm 1^{\circ} \mathrm{C}\right)$ (Fig. B), a decrease was also

observed in the values, but it was less than the effect of storage at laboratory temperature where the above values of fresh egg yolk lipid of quail, hen, duck and goose were decreased to $1.144,1.113,1.260$ and 1.221 respectively, after 30-days of storage. Moreover, they were 
continued to decline to the end of the storage period (60-days) whereas it reached to 0.955 , $0.933,1.072$ and 0.967 for the above egg types respectively. This may be due to the effect of storage, especially at laboratory temperature, which led to reducing the concentration of active compounds in lipid, including tocopherols and carotenoids and this is reflected on the mechanism of action of antioxidants.
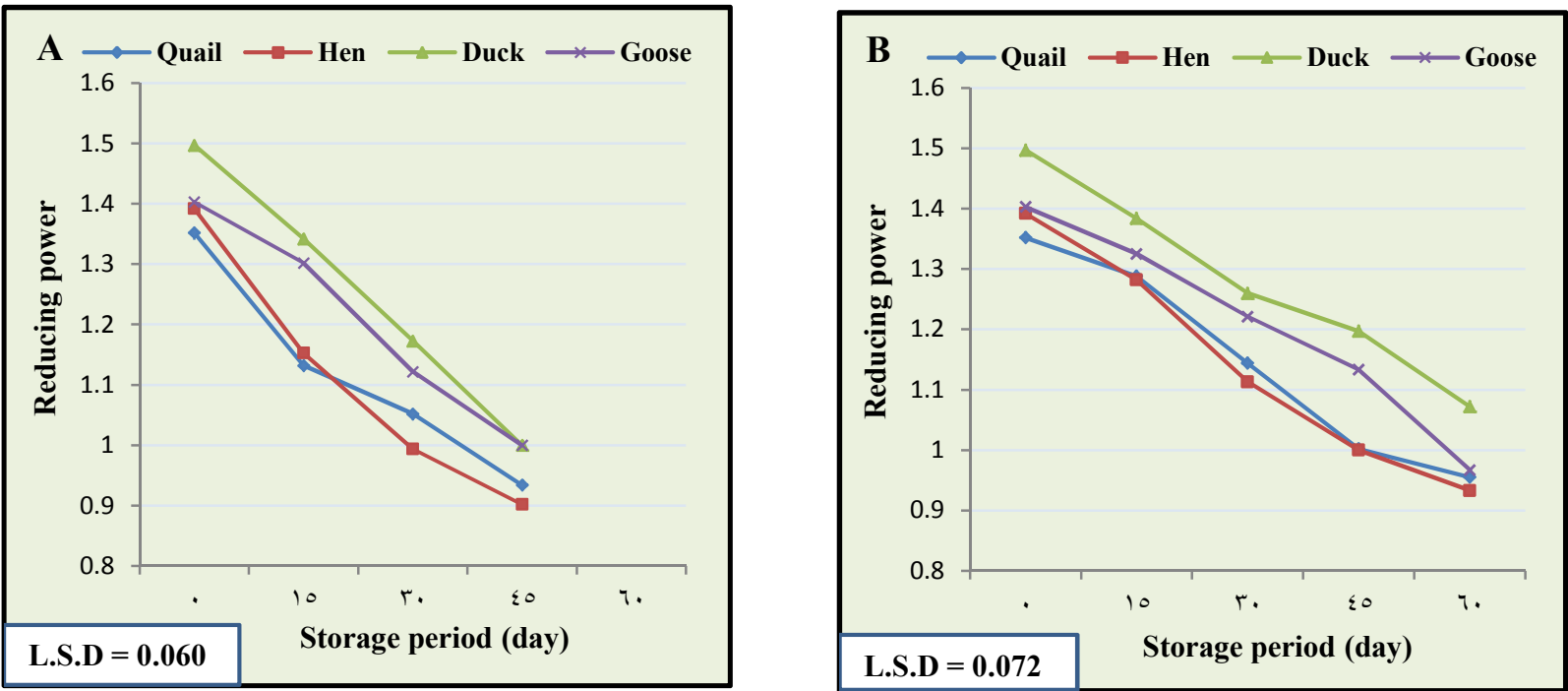

Fig. (2): Effect of storage on the reducing power of yolk lipid, A: Laboratory temperature (2530) ${ }^{\circ} \mathrm{c}, \mathrm{B}$ : Refrigerator temperature $(4 \pm 1)^{\circ} \mathrm{C}$.

\section{Effect of storage on the Chelating of iron ions of yolk lipid}

The results in Fig. (3) showed the effect of storage at laboratory temperature (A) and refrigerator temperature (B) on chelating of iron ions of quail, hen, duck and goose yolk lipid. Results showed a significant decrease in chelating of iron ions with continuous of storage period, and the storage at the laboratory temperature had a clear effect in reducing the chelating of iron ions values compared to the refrigerated storage. In Fig. (A), the chelating of iron ions decreased from $57.37 \%, 55.17 \%, 53.75 \%$ and $52.53 \%$ for yolk lipid of quail, hen, duck and goose eggs before storage respectively to $48.23 \%$,
$47.38 \%, 46.76 \%$ and $45.34 \%$ after 15 -days of storage and continued to decline, whereas it reached in the end of storage period (45-days) to $40.97 \%, 39.82 \%, 37.84 \%$ and $38.05 \%$ for the above egg types respectively.

Fig. (B) shows the effect of storage on chelating of iron ions of yolk lipid at refrigerator temperature $\left(4 \pm 1^{\circ} \mathrm{C}\right)$, the results of the statistical analysis showed significant differences in chelating of iron ions during the storage period, the chelating of iron ions for yolk lipid of quail egg decreased from $57.37 \%$ before storage to $45.60 \%$ after 60 days of storage at refrigerated, and for hen from $55.17 \%$ to $44.16 \%$, and for duck from 

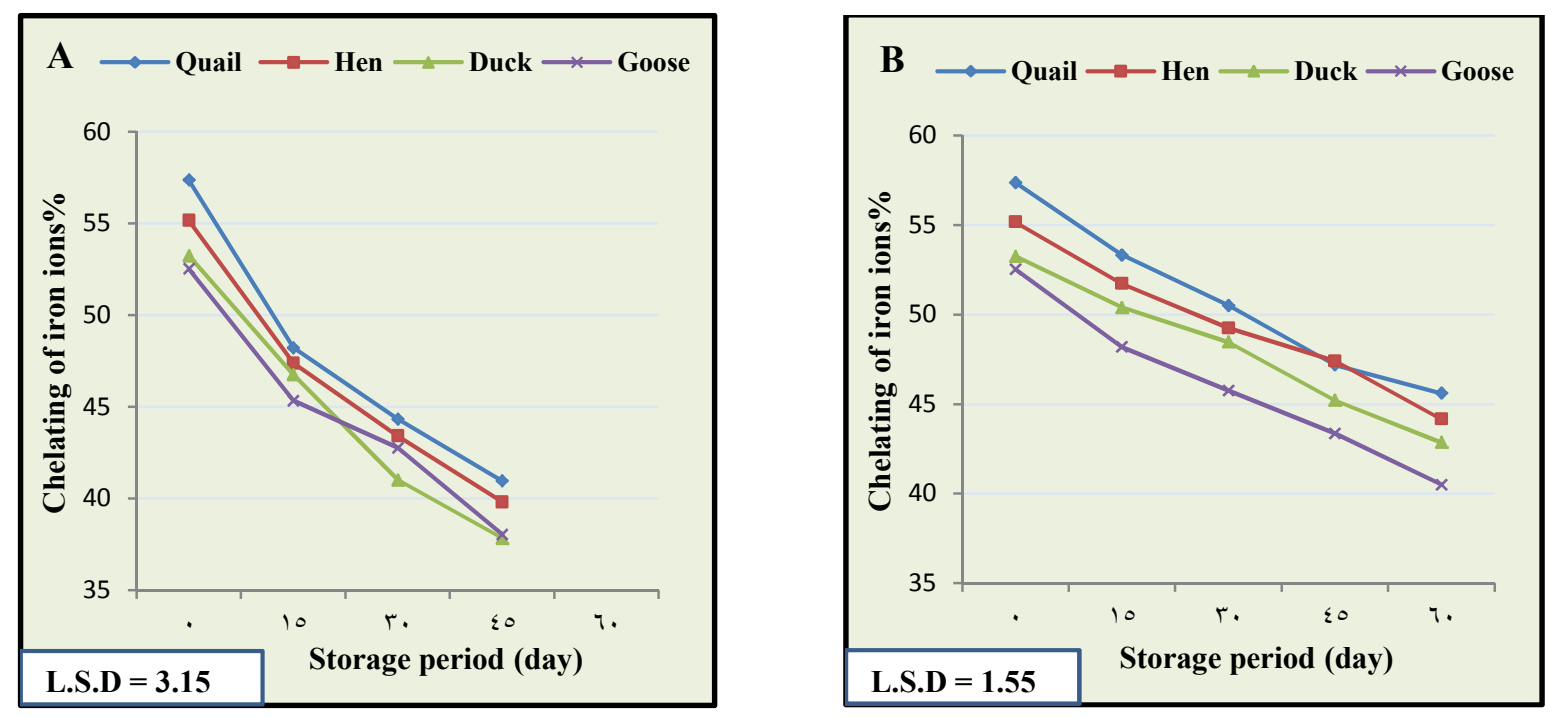

Fig. (3): Effect of storage on the chelating of iron ions of yolk lipid. A: Laboratory temperature $(25-30){ }^{\circ} \mathrm{C}$, B: Refrigerator temperature $(4 \pm 1)^{\circ} \mathrm{C}$.

$53.25 \%$ to $42.86 \%$ and for goose from $52.53 \%$ to $40.49 \% .53 .25 \%$ to $42.86 \%$ and for goose from $52.53 \%$ to $40.49 \%$. This difference of chelating of iron ions reduction for all extracts and lipid may be due to the difference in birds type as well as to the difference effect of storage periods at different temperatures on the specific and sensory characteristics of eggs, this is in line with what Abdul Mahdi (2009) have stated that the high quality of eggs begins to gradually deteriorate over time and the speed of degradation depends on the conditions of storage, circulation and marketing.

\section{Effect of storage on the Scavenging of hydrogen peroxide of yolk lipid}

The results in Fig. (4) showed the effect of storage on the scavenging of hydrogen peroxide of yolk lipid stored at laboratory temperature (A). The results showed significant differences $(\mathrm{P}<0.05)$ for the values of scavenging among the studied egg types and there was a significant effect $(\mathrm{P}<0.05)$ for storage on the scavenging of hydrogen peroxide, so there was reduction in scavenging with continuation of storage period, the values before storage were
$50.42 \%, 52.14 \%, 50.47 \%$ and $56.71 \%$ for quail, hen, duck and goose respectively, the values decreased during storage after 15-days to $42.95 \%, 46.32 \%, 41.09 \%$ and $49.16 \%$ for the above types respectively and the reduction continued to the end of storage period (45days), whereas it reached to $35.13 \%, 39.73 \%$, $34.64 \%$ and $42.24 \%$ respectively.

When the egg stored in the refrigerator $\left(4 \pm 1^{\circ} \mathrm{C}\right)(\mathrm{B})$ was also observed a reduction in the values, but the reduction was less than the effect of storage at laboratory temperature, as the above values for fresh egg yolk lipid decreased to $43.84 \%, 45.63 \%$ and 44.56 and $50.39 \%$ for egg of quail, hen, duck and goose respectively, after 30-days of storage and continued to decline to the end of storage period (60-days) to $38.72 \%, 40.58 \%, 39.41 \%$ and $45.53 \%$ for the above eggs types respectively, this may be due to the effect of storage, especially at the temperature of the laboratory. Moreover, this led to reduce the concentration of active compounds in When the egg stored in the refrigerator $\left(4 \pm 1^{\circ} \mathrm{C}\right)(\mathrm{B})$ was also observed a reduction in the values, but the reduction was less than the effect of storage at laboratory temperature, as the above values for fresh egg yolk lipid 

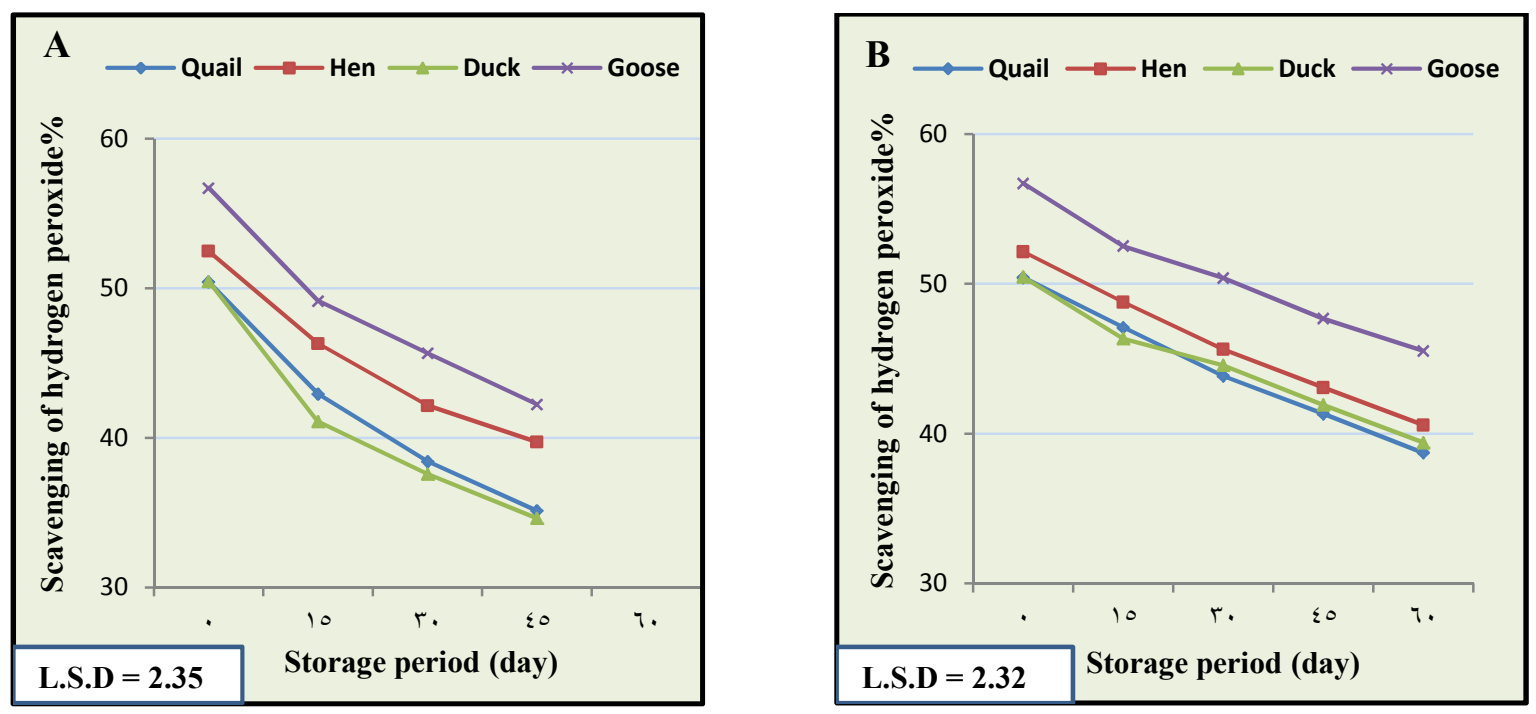

Fig. (4): Effect of storage on Scavenging of hydrogen peroxide of yolk lipid A: Laboratory temperature (25-30) ${ }^{\circ} \mathrm{C}$, B: Refrigerator temperature $(4 \pm 1){ }^{\circ} \mathrm{C}$.

decreased to $43.84 \%, 45.63 \%$ and 44.56 and $50.39 \%$ for egg of quail, hen, duck and goose respectively, after 30-days of storage and continued to decline to the end of storage period (60-days) to $38.72 \%, 40.58 \%, 39.41 \%$ and $45.53 \%$ for the above eggs types respectively, this may be due to the effect of storage, especially at the temperature of the laboratory. Moreover, this led to reduce the concentration of active compounds in lipid which include tocopherols and carotenoids, and this is reflected on the mechanism of action of antioxidants.

1- The lipid of goose egg yolk gave the highest antioxidant activity compared to duck, hen and quail eggs yolk.

2- The antioxidant activity of yolk lipid for all egg types have been affected by storage and different storage conditions (room temperature and temperature of the refrigerator).

3- The decrease in the antioxidant activity of yolk lipid for all eggs types and all of the chemicals.
4- The decrease was more for yolk lipid of egg types in storage at room temperature compared to storage at refrigerator.

\section{Acknowledgements}

The authors would like to thank the Department of Food Science and Biotechnology, College of Agriculture, University of Basrah for all facilities and equipment provided.

\section{References}

Abdul Mahdi, H.A.Z. (2009). Effect of dring and storage methods and some food additives on functional properties of liquid and egg white. Coll. Agriculture, Univ. Basrah: 114 pp.

Akter, Y.; Kasim, A.; Omer, H. \& Ournisazili, A. (2014). Effect of storage time and temperature on the quality characteristics of chicken eggs. Journal of Food, Agriculture and Environment, 12 (3\&4): 87.

Al-Hilfi, A.Z.H. (2016). Extraction, purification and characterization of protein hydrolysates from fish and Shrimp by- 
products and assay efficiency in beef patties storage. Ph. D. thesis. Coll. Agric., Univ. Basrah : 171pp.

Al-Hilfi, S.A.H \& Al-Moussawi, U.B.H. (2011). Phenolic content and antioxidant activity in some spices and herbs. Journal of Iraqi Agriculture and Research, 16: 210218.

Al-Tai, M.A. \& Al-Moussawi, U.B.H. (1992). Practical Technology of Meat and Fish. Coll. Agriculture, Univ. Basrah Press: 142pp.

Anton, M.; Castellani, O. \& Guérin-Dubiard, C. (2007). Phosvitin. Pp: 17-24. In: Huopalahti, R.; López-Fañdino, R.; Anton, M. \& Schade, R. (Eds.). Bioactive Egg Compounds. Europe. Springer Press: 298pp .

Chen, Y.; Chang, H.; Wang, C. \& Cheng, F. (2009). Antioxidant activity of hydrolysates from duck egg white using enzymatic hydrolysis. Asian- Aust. J. Anim. Sci., 22(11): 1587-1593.

Decker, E.A. and Welch, B. (1990). Role of ferritin as a lipid oxidation Catalyst in muscle Food. J. Agri. Food Chem., 38(3): 674-677.

Gulcin, I. (2005). The antioxidant and radical saving activities of black peper (Piper nigrum) seeds. International Journal of Food Science and Nutrition, 56 (7): 491499.

Hatta, H.; Kapoor, M. \& Juneja, L. (2008). Bioactive components in egg yolk. Pp.: 185-237. In Mine, Y. (Ed.). Egg Bioscience and Biotechnology. John Wiley \& Sons, Ltd. Hoboken, New Jersey: 362pp.

Lakins, D.G.; Alvarado, C.Z.; Luna, A.M.; O'Keefe, S.F.; Boyce, J.B.; Thomson, L. D.; Brashears, M. T.; Brooks, J.C. \& Brashears, M.M. (2009). Comparison of quality attributes of shell eggs subjected to directional microwave technology. Poultry Science, 88(6): 1257-1265.

Li-Chan, E.C.Y. \& Kim, H.O. (2008). Structure and chemical composition of eggs. Pp: 1-95. In Mine, Y. (Ed.). Egg Bioscience and Biotechnology; John Wiley \& Sons. Ltd. Hoboken, New Jersey : 362pp.

Nimalaratne, C.; Bandara, N. \& Wu, J. (2015). Purification and characterization of antioxidant peptides from enzymatically hydrolyze chicken egg white. Food Chem., 188: 467- 472.

Nimalaratne, C \& Wu, J. (2015). Hen egg as an antioxidant food commodity: A review. Nutrients, 10: 8274-8293.

Osawa, T. \& Namiki, M. (1981). A novel type of antioxidants isolated from leaf wax of Eucalyptus leaves. Agri. Biol. Chem., 45: 735-739.

Oyaizu, M. (1986). Studies on products of browning reaction: Antioxidant activities of products of browning reaction prepared from glucosamine. Japan. J. Nut., 44: 307315 .

Pearson, D. (1970). The Chemical Analysis of Food. $6^{\text {th }}$ Chemical publishing company, Inc., New York: 604pp.

Ruch, R.J.; Cheng, S.J. \& Klaining, J.E. (1989). Prevention of cytotoxicity and inhibition of intracellular, communication by antioxidant catechins isolated from Chinese green tea. Carinogen., 10: 10031008.

SPSS. (2009). Statistical packages of Social Sciences. Version 15 for window SPSS. Inc.

Surai, P.F. (2006). Selenium in Nutrition and Health. Nottingham, Nottingham Univ. Press: 974pp. 